\title{
Between "Normalization" and Spectacularization: Representing Violence Against Women in TV Crime Series
}

\author{
Francesca Lopez \\ Roma Tre University, Rome, Italy
}

\begin{abstract}
This research in the field of Media Sociology and Gender Studies compares the representation of death and of female corpses in two crime TV series produced in the last decade in two very different contexts: the Italian series RIS - Delitti imperfetti (Canale 5) and the Irish one The Fall (BBC Northern Ireland). The interest for this theme is born out of the awareness of the gravity of a phenomenon such as gendered violence. The starting assumption here is that media representations play a key role in fueling or counteracting the culture that feeds gendered violence: this is true both for news media and fictional media, able to shape our social imaginary. At the basis of this research there are three questions: whether the violence, victims and perpetrators represented in media coincide with the actual reality of the above-mentioned countries; what kind of frame is the most commonly used to represent male violence against women; and whether violence itself and the dead female body are represented with any kind of eroticization or spectacularization. To answer these questions, I will carry out a quantitative and qualitative analysis, looking at Feminist Film Theory in order to resolve he last issue.
\end{abstract}

Keywords: gender-based violence; gendered violence representation; media studies; gender studies; gender and media studies; corps

\section{Introduction}

This research project focuses on the representation of male violence against women and on the fetishization of women's death in crime TV series. The author explores this topic by comparing two "cop shows" that have been produced in different countries in the same period: RIS-delitti imperfetti, TaoDue, Italy 2005-2009, and The Fall, RTE One, UK, 2013-2018.

The research questions are the following: (a) Do the typologies of victims, perpetrators, and stories that are more recurrent in the two series coincide with those more diffused in reality? (b) Is violence against women framed in terms of individual aberration or as a socio-cultural problem rooted in gender power relations? (c) Which visual "regime" prevails in the two series? (d) Are the violence scenes or victims' bodies eroticized or in other ways spectacularized? Finally, the author aims to investigate if any difference is found in the two series and if these differences can be traced back to the different socio-cultural contexts of their countries.

The interest for this topic arises from the awareness of the relevance of gender based violence: In Italy, every year over 164 women are killed by men; $2 / 3$ of which are killed by their partners, ex-partners, or relatives (Eures, 2015). The media representations play a key role in promoting or hindering the culture of gender-based

Francesca Lopez, Master's degree in Film, Television and Multimedia Production; Assistant Professor, DAMS Department, Roma Tre University. 
violence. The assumption underpinning this research is grounded in social constructivism, according to which social reality is constructed in and through social interactions, especially through communicative interactions and discoursive practices. Among these practices, media representations and consumption processes play a key role (McQuail, 2007, p. 271). Although factual media and genres (news media above all) result more influent in influencing public opinion, and also fictional genres are very powerful in shaping collective imagery and the ways, in which people perceive social phenomena and their actors (Buonanno, 2012). Moreover, TV series seem to be firmly grounded in audience's consumer habits and they are able to generate cult phenomena (Innocenti \& Pescatore, 2008). This is even more true since new formats and distribution platforms, such as Sky Video on Demand or Netflix, have become available (Scaglioni \& Barra, 2013; Grasso \& Penati, 2016).

\section{Literature Review}

In Italy, there are few studies on media representation of male violence against women and they are focused mostly on news media (Gius \& Lalli, 2014; Giomi, 2015), while fiction genres are practically unexplored (to the exception of recent works, such as Giomi \& Magaraggia, 2017). This is surprising, given that violence against women is one of the preferred narrative subjects of several media genres, such as thriller, horror movies, and TV series. This is true in particular for crime TV series that, since the $80 \mathrm{~s}$, have been a privileged site for applying the "sex and violence" combination, which seemed to be a powerful recipe in the free market of television environment.

The most relevant contributions on media representation of male violence against women come from English speaking countries, where numerous essays have been dedicated to the relationship between gender-based violence and popular culture (Shepherd, 2012). Scholars agree that the representation of violence against women undergoes a process of fetishistic sensationalization in many popular culture media forms. This aesthetics is has been defined as fleshography by Pinedo (1997) and autoptic vision by Tait (2006). According to Pinedo, death and pornography images share many elements, as they both not only, "break the taboo, but also expose the secrets of the flesh, pouring out the content of the body: porno does it by carnal union, horror by carnage" (Pinedo, 1997, p. 61). This analysis, originally developed by Feminist Film Criticism, describes porno and horror as cinematographic body genres (Thornham, 1999, p. 3). Death and pornography images are comparable to the ones of many crime TV series, such as CSI (Crime Scene Investigation) (CBS, 2000-2015), centered on New York Scientific Police Department. According to Tait (2006), the numerous autopsy sequences produce a fleshography revelation that allows the audience to have an autoptic and hyperreal vision of the human body, with the video cameras penetrating inside its viscera.

According to Sawday, "examination and dissection are carried out with a pedagogic claim allowing a re-proposal of the obsessive eroticism that imbued the Renaissance culture, before the ideal of a neutral field of enquiry" (2013, p. 5). Tait (2006) claimed that such a necrophiliac view also distinguishes the typical aesthetics of crime TV series, like CSI, which show off forensic art as a tool to perform a pornography of death, according to the logic that puts the spectator in the position of getting pleasure from those images.

Despite the fact that all this refers to both male and female corpses, in the latter case, erotic implications become more evident: Female victims, as a matter of fact, are almost always young and beautiful, their body remains attractive despite its brutalization and images of their autopsy are alternated with the ones of their death, often loaded with sexual symbolism. The popular and recent crime series-The Fall (BBC, 2013) has been considered emblematic of a glamourization of female death: Young women corpses-washed, adorned, 
and recorded by the serial killer-are fetishsed and the whole aesthetics of the program encourages a necrophiliac view (Jermyn, 2016).

\section{Methodology}

The methodological apparatus used in the analysis comes from the two main traditions within Feminist Media Studies: Feminist Film Theory and Feminist Culturalist Television Criticism. Despites their differences (for an effective description, Pravadelli, 2006), they share a constructivist perspective and look at how media representations of masculinity and femininity "offer ideological frameworks to the process through which men and women interpret, define their own gender identity" (Thornham \& Purvis, 2005, p. 113). In order to analyze the series, the author uses textual analysis, paying attention, as in the tradition of Feminist Film Theory, to how the rhetorical-formal devices structure gender difference and to which views on the male-female relationship is expressed in the analyzed TV series (Pravadelli, 2006, p. 146).

Moreover, the author has availed a quantity analysis methodology that has allowed me to identify:

- The most common typologies of violence represented (IPV, violence committed by a person unknown to the victim and violence committed by relatives or ex partners).

- Common ground and differences between the two TV series in the representation of the types of violence mentioned.

- The correspondence with the reality, or rather if this type of representation of gender based violence result deceptive or instead reflects the socio-cultural referred context.

- Eventually, a particular emphasis has been given to the visual plan. The visual analysis resulted essential for a focus on female corpses, sexualized and fetishized even though death conditions, most of the times, turn out to be not erotic at all.

\section{Results}

The results of this study show how the representation of gender-based violence often appears misleading, non-corresponding to the real context, in which some specific dynamics are reiterated. "Sex and violence" turn out to be an infallible recipe to keep the viewer glued to the screen and to win his/her loyalty. Furthermore, the imaginary built on a certain type of representations contributes to violence "normalization" process. This happens because, according to Gili (2006), violent images can rise a pathos that mass media would not be able to get in other way.

I will gradually show how, in mass-media representation, violence assumes different shapes, and also the way in which social actors are positioned in a prescriptive way, using power dynamics between gender as a reference model.

\section{Representation of Different Typologies of Violence}

The present analysis investigates two crime tv series: RIS - Delitti Imperfetti and The Fall. The latter, an Irish TV series broadcasted for the first time in 2013, turned out to be more innovative than RIS - Delitti Imperfetti, an Italian TV series produced in 2005. In The Fall, Stella Gibson (Gillian Anderson) is in charge of the investigation to find the serial killer who terrorises the whole city of Belfast. The perpetration of violence is represented as a typical male conduct and so, horizontally, the storyline concerning a serial killer murdering young women turns out to be a common trait of many other TV series. 
But a closer look to the vertical storyline shows a real innovation. Violence against women stories are of different kinds: assaults by colleagues (as is the case of Stella Gibson, assaulted by a policeman), IPV (intimate partner violence - Spector, the killer, is a domestic violence expert psychologist; the leitmotiv of the series is the story of a woman, victim of an abusive husband, who turns to Spector for help), pimping and murders by some businessmen.

This binarity in the narration proves to be really advanced, but also allows for a deeper analysis of the typologies of violence, all very similar to each other although they are still different.

The types of violence represented are three in total: violence committed by a person known to the victim, violence committed by a person unknown to the victim, and domestic violence (IPV). Each of them has both a different narration and a different categorization of victim and prosecutor.

Violence committed by a person known to the victim, as a relative or a person close to him/her, seems to be very similar to IPV. This latter, tritely called "domestic violence", serves as leitmotiv for the narration that, no matter how paradoxical, is the decisive key of interpretation of the series, making the killer a "normal man", the man next door, in which the viewers can easily recognise themselves.

In both TV series, the use of violence against women is represented as a typical male conduct, that "creates the difference" between the sexes, although it does not derive from an essentialist matrix; on the contrary, it is an effect and at the same time a tool for reiterating gender disparity, not residual phenomenon of our society, but rather constitutive category of reality (Giomi \& Magaraggia, 2017).

Violence committed by a person unknown to the victim, instead, is used as the main device for a sensational narration and for keeping the viewer glued to the screen. This is the "stranger danger" subject (Greer, 2015, p. 100), in other words, the intentionally misleading representation of the menace to the physical and sexual integrity of women as something coming from the public space. This mystification constitutes an integral part of the cautionary tale function of sexual violence chronicles: tales of "admonition", imposing appropriate behaviours to women, otherwise they risk being assaulted (Boyle, 2005, pp. 94-122).

It is unsophisticated and decisive, or so this representation of violence appears; although, at the same time, it turns out to be the most dangerous because it does not reproduce reality, but rather it distances violence from its condition of a prescriptive phenomenon of gendered violence, at the basis of our society. According to Eurostat (2015) data collected, victims killed by known persons are just 1/3 of the total.

Differently to The Fall, in the TV series RIS, we do not find a twist in the vertical and horizontal storyline. The story takes place in the Scientific Investigation Police Department of Parma and talks about the resolution of complex and mysterious cases. In the fourth season, the one the author focused on, the killer, Andrea Gherdin, murders blue eyes 18-year-old girls. There is no IPV violence committed by victims' relatives, except in a few episodes. Of the overall 89 episodes, just $4(4 \%)$ talk about IPV cases: an attempted rape $\left(4 \times 18^{1}\right)$, two femicides $(3 \times 10 ; 3 \times 12)$, and repeated blows $(5 \times 7)$. Instead, 38 episodes $(43.6 \%)$ tell about sexual and/or lethal violence committed by persons unknown to the victim, for a total of 12 victims, included female members of RIS.

However varied the differences between the types of violence are, one of the common points remains the spectacularization of the violence itself, the ability of the mass media to make it pleasant, sweetening it using "frames" that encircle the narration. This process allows to normalize the violence through different devices, such as erotization, fetishization, and sentimentalization, which the author will debate in the next paragraphs.

\footnotetext{
${ }^{1}$ In TV series production, the first number states the season and the second the episode.
} 


\section{Frames}

Gender-based violence is part of many branches of the cultural industry, as it is placed in that "sex-violence" package that turns out to be an infallible recipe from an emotional standpoint.

"The notion of frame is very useful to explain the rule of the mass media in the social construction of reality, of its subjects, phenomena and processes" (Giomi \& Magaraggia, 2017, p. 44). According to Marini (2006, p. 184), "the frame represents the way a means of communication uses to give a meaning and a particular point of viewing the theme". The frame contains causes and effects of a specific phenomenon, clarifies how social happenings are placed inside the collective imaginary, and contributes to an easiest comprehension of the phenomenon. In particular, "the frame guides to the identification of responsibility and cause of a specific event or social problem" (Scheufele, 1999 p. 90).

With regard to gendered violence, the frame assumes an essential role for the definition of the violence itself. All mass media narrations that move gender-based violence to the individual aberration plan use an "episodic" frame, "focused on the evenemential element, amplifying the incidence of subjective factors and peculiar circumstances and suggesting that we are facing an isolated episode" (Giomi \& Magaraggia, 2017, p. 45). This is precisely what happens in RIS, where the perpetrator of the violence become an aberrant figure, continuously defended by a justification strategy, such as the pathologization that finds the cause of the violence in the traumatic and tumultuous life of the torturer.

The "thematic" frame, on the other hand, describes a social event as a wider phenomenon, giving details about its incidence and spreading and showing the factors that contributed to it (Giomi \& Magaraggia, 2017, p. 45). We can find this kind of frame, instead, in The Fall when the protagonist, at a certain point in the series, describes violent men not as monsters, but rather, as the detective says, just men.

Despite the originality of the themes of this series and the realistic key of interpretation of violence, in the last season the killer is pathologized exactly as in $R I S$, relegated to the limits of alterity and violence, here categorized as socio-cultural structured and structuring constructs. Both the killers are classified as "crazy" or "monsters" because of their strong lack of love and their addiction to psychotropic substances that lead them to act violently.

The main problem is precisely this: mass-media coverage of male violence against women uses mainly the episodic frame, avoiding treating violence as a rooted socio-cultural construct that must be discarded.

All this contributes to ensuring, firstly, the justification of the perpetration of the violence and secondarily, to lack of identification of the referred audience in the torturer, because this representation leads to assume that the protagonists - who commits violence, who suffers the consequences of it, or both of them - are "subnormal" (Sotirovic, 2003). The threat to the physical and sexual integrity of the women appears, thus, as something coming from the public space.

Although, on closer inspection, it becomes clear that something is changing in the Italian landscape. Referring to the 2016 edition of "Monitoring the female representation in Rai TV programs" (Gaudio et al., 2017), to which the writer contributed, one can note a section dedicated to the quantitative and qualitative forms of treating genre violence.

The perpetrators unknown to the victim still result overrepresented (32 cases, $37.6 \%$ of the total), but almost two third of the perpetrators of gender-based violence cases showed by public television ( 54 cases, $65 \%$ of the total $)^{2}$ belong to the same family background $(i v i, 32)$, in line with Italian femicide statistics data.

\footnotetext{
${ }^{2}$ The total is higher than 100 , as the question required multiple answers.
} 
Concerning the conceptualization of violence, the layout of gender relations is singled out in a wide range of cases $(41,49 \%$ of the total), but the same happens, unfortunately, also for the key of interpretation of the individual aberration (32 cases, $37 \%$ of the total). Positive are, instead, the data collected on the lowered deviation of the use of episodic and thematic frame: If the first remains the more widespread $(57 \%, 47$ programs), the second appears in $43 \%$ of the cases (36 programs); Cinema and fiction areas are more critical, because the more pronounced inclination to dramatization and sensationalization opts for the episodic framework, respectively, in the $67 \%$ and $73 \%$ of the cases (ivi, 33-35).

\section{Representation of the Victims}

In the narrative construction of sexual violence against women another phenomenon emerges: Is the "victim blaming", the Italian "rivittimizzazione" or "vittimizzazione secondaria" (Boyle, 2005, pp. 94-122, as cited in Giomi \& Magaraggia, 2017).

This consist in blaming the victim, that not only suffers physical, moral, and psychological damages, but is also forced to expiate the faults of wearing some kind of clothing and of being in a certain place at a certain hour, because is insinuated that is the victim herself who has provoked the violence with her behaviours (Boyle, 2005, pp. 94-122, as cited in Giomi \& Magaraggia, 2017).

This leads to divide the victims in "good" or "bad", in "she-asked-for-it" and "unfortunately-it-happened-to-her" kinds. "Good" victims are those who respect all the rules of the feminity, who do not cross their home threshold, who do not go out of the ordinary. "Bad" victims are, instead, those who dare think outside the box, the emancipated, autonomous, and independent, masters of their own life.

The peculiarity of mass-media coverage of violence is the same ability to remove responsibility from the persecutor in different ways. Beyond revicitimization, representation of violence, especially of the IPV kind, results misleading even because of another reason, that is the "conviction that most of what is called violence is actually an ordinary reaction to a couple conflict" (Boyle, 2005, pp. 94-122, as cited in Giomi \& Magaraggia, 2017).

According to Giomi, from a particular point of view, male IPV in mass media debate is exorcized throughout the choice of extreme cases and of frame that present it as an aberration, even as an individual pathology while, from another point of view, it is normalized as a recurring event in sentimental relationships (Boyle, 2005, pp. 94-122, as cited in Giomi \& Magaraggia, 2017). This produces a deleterious relocation of violence representation that, instead of being described and constructed as a socially and historically existing phenomenon that is culturally rooted, is normalised and brought back to the romantic love frame - that is to say, violence is sentimentalized, as it happens with partners' jealousy or possessiveness.

The whole process of "re-victimization" and encircling of violence in the romantic love frame is typical of RIS. More than half of the narration is based, indeed, on stories of violence and cases of re-victimization. However, the register used in the TV series The Fall, belongs more to the spectacularization of death of the victims of violence.

Erotization and fetishization are at the basis of the representation of female corpses. Analysing the Irish TV series The Fall, Jermyn catches even sight of the so-called "glamourization" (as in the advertising) of female death. Young women's corpses, cleaned, adorned, and posed by the serial killer, are transformed into erotic fetish objects, and the whole aesthetic of the program invites the audience to a necrotic gaze (Jermyn, 2016). The peculiarity is that female death is turned into an erotic show, even in circumstances with no sexual 
connotation, and this phenomenon is very popular in cop shows, so much so that it gave birth to the crime porn label (Jermyn, 2016, p. 18).

In $\mathrm{TV}$, the normalization of such a gaze found an even more extreme impulse and conjugation in another crime TV series, CSI (CBS, 2000-2015), in which the viewer is lead to find pleasure from the "fleshography revelation" produced by framing inside the corpse and by the effects of the violence on it (Tait, 2006, p. 50): this pornography of death, indeed, is posed as a witness to the greatness of science and of the edifying truth operation it makes possible. It is, nonetheless full of gender connotations: indeed, we can find further arguments supporting the different meanings of female and male corpses in mass-media contemporary culture. In CSI, victims often lose their lives because of sexual violence or violent sex, but women are treated in a different way. Despite of the brutalization, their beauty remains untouched and their corpse still has an erotic connotation, even after death, as is evident by syntaxes of the images that accurately avoid the erogenous zones, but on the other hand, alternates autopsy scenes and flashbacks of the lethal accident, with all its hot details. The necrophiliac imaginary of the series winks to the young heterosexual male viewer, concludes Tait (ivi, 56-57), and it sees the female body, previously alive, as a place of violence and desire (Giomi \& Magaraggia, 2017). We can find the same visual register of "hyper reality" and "autoptic vision" (Tait, 2006) in RIS, Italian scaled version of $C S I$.

In her analysis of female representation in poetry, Bronfen notes that the death of a woman tickles the male gaze that, in that moment, which can, in that moment, carry out its undisturbed power. Dillmann, too, tries to answer the question of the central role of women in fetishized deaths. Her argument revolves around the agency of the female image: whether the dead woman in question is robbed of her agency when her life ends, whether she finally assume an unempowered role, and not an empowered one as she was used to before her death. The loss of the agency and the outplacement in an unempowered role allows the man, once again, to dominate the woman by exercising his power, a phenomenon that in literature is named "economy of the gaze".

As asserted by Edgar Allan Poe, "the death of a beautiful woman is, unquestionably, the most poetical topic in the world". In many crime TV series, this kind of fetishist representation is evident.

The sexual fetishist representation, lethal or not, is the most common form of violence in the collective imaginary. One of the first and most exhaustive studies was made by Projansky (2001), who spent 10 years collecting and analysing images of rapes in United States cinema and TV at the beginning of the 20th century: her exploration started from the period when Hollywood still prohibited this kind of explicit representations, suggesting in the Production Code of 1930 - effective only from 1934 - to use less direct and more transversal forms. Nonetheless, according to Projansky, those forms are so deeply rooted in our imaginary that they naturalize rape, not just as a physical event, but also as a part of our daily fantasies, fears and practices of consumption (ivi, 3).

Feminist critic introduced, with regards to this, the concept of rape culture (Buchwald, Fletcher \& Roth, 2005): a culture in which rape is the most serious form of a continuum of sexual violence women suffer daily.

\section{Conclusions}

The overall conclusions of the investigation allow the author to answer to the questions at the beginning of the present paper.

After analysing victims and perpetrators in the two TV series (RIS - Delitti Imperfetti and The Fall), one can note that the mass-media context differs from the referent context of reality, above all with regards to Italy. 
In mass-media representation, victims are always young and beautiful women, while in the Italian reality, women killed by men are of a different age range, between 40 and 60 years old. An EURES survey confirms that female victims aged between 0 and 17 years old are the less affected (10 victims), while the ones aged over 44 years old are the $63.2 \%$ of the total (Giomi, 2015b). Equally worrying are the data from the Irish reality. According to EURES (2015) data collection, the country is even one step ahead of Italy with regard to femicide victims, which are mostly aged between 40 and 50 years old.

This happens because the idea of an aged woman is not as attracting as the one of a young and beautiful girl, but also because the re-victimization process is easiest to put into practice. An aged woman, unlike a young girl, would not violate the whole set of rules of the "female regulation", that leads to side re-victimization or victim-blaming: going out late at night, hanging around with ambiguous people, wearing a particular dress, and so on.

Moreover, in the same mass-media representation, femicide victims are killed by strangers, despite what happens in the real world, where the main perpetrators are relatives, partners, or ex partners. In Italy, 2/3 of feminicide victims (Eures, 2015) are assassinated by their own partner; in Ireland, the percentage of this kind of murders is smaller but data also reveal that the percentage of persecutors known and unknown to the victim is the same (19\%). This means that in Italy, lethal IPV is the most widespread genre violence, while in Ireland it is present on a smaller scale.

Nonetheless, mass-media representation is focused exclusively on violence committed by strangers. And this happens because the above-mentioned debate: everything is about selling a product. What attracts the public most? What keeps viewers glued to the screen? Nothing quite like the mystery of a young woman murdered by a stranger, better still if it is a mentally ill person or an immigrant. As seen before, for the purposes of a proper overview of IPV, and more generally, of male violence against women, it is essential to analyse all this in the light of gender relations (and differences).

Vice versa, disquisitions presenting this as a direct result of individual deviance often lead to mystification and undermine the possibility to develop effective interventions. Those argumentations are, though, the most widespread and they affect different mass-media categories and geopolitical contexts, as they lend themselves better to dramatization and sensationalism, essential for stealing competitors' audience (Giomi \& Magaraggia, 2017).

The episodic frame turns out to be, therefore, the most widespread, even if initially The Fall appeared, from this point of view, very innovative in its representation of the killer as a "normal man", using a realistic representative style encircled in the thematic frame. However, in the last season, the killer is again categorized as a "monster", into that aberrant and perverse role that downgrades violence to a deeply-rooted cornerstone phenomenon of our society, exactly as it happens in RIS. This, indeed, puts the persecutor in the frame of individual aberration, performing just one kind of violence that is the one committed by serial killers; The Fall, instead, performs different types of violence within the larger sphere of gender relations.

Ultimately, the author analysed the visual regimes prevailing in the two TV series investigated. In The Fall a fetishist and aesthetic pattern prevails repeatedly. The death of young victims becomes so much the heart of the narration that it could easily be considered as a protagonist of the horizontal storyline. The "flashography revelation" (Pinedo, 1997, p. 61) punctuates the death images jeopardizing the same narration, the characters' dialogues and the plot. 
Notwithstanding fetishization belongs mainly to the visual register of The Fall, also RIS is certainly interesting in this sense. The latter, by its artificial approach, presents corpses hyperrealistically and autoptically (Tait, 2006). Influenced by CSI, RIS sweetens female death representation by a scientific and medico-legal register, contributing to the normalization of the necropornographic gaze.

To sum up, it is evident that, despite geo-cultural differences between the two TV series analysed, they use the same register based on the fetishization of female death and normalization of gendered violence. This majorly demonstrates that gender connotations permeate the whole mass-media system and that the power dynamics, translated into "economy of the gaze", belong to the collective imaginary in which we all are immersed.

Therefore, if the mass-media contents investigated offer a highly sensationalized aesthetic of gender-based violence, it is necessary to find alternative forms of representation that could be able to subvert the toxic narration, practices of representation that could demonstrate that we do not really need to use fetishized images of female corpse inappropriately, but we need to return an imaginary as close as possible to the real experience of violence.

According to Virdi's analysis of Hindi cinema, in the representation of violence scenes it is essential to pay specific attention to the face of the woman and to its passage from terror to pain. In this way, the woman would appear as the subject of the scene and one can do justice to her specificity rather than dehumanize her and reduce her to an object, with no individual peculiarities. So, it is possible to assert that a grammar of positive images could produce a counter-narrative that would do justice to the gravity of the phenomenon and would avoid the normalization of the violence and the erotization of female corpses throughout the framing of the entire body, an approach that makes violence an end-in-itself enjoyable performance, without considering the aberrant consequences caused by that this kind of vision.

\section{References}

Boyle, K. (2001) What's Natural about Killing? Gender, Copycat Violence and Natural Born Killers. Retrieved from https://doi.org/10.1080/09589230120086511

Boyle, K. (2005). Media and Violence: Gendering the Debates. London: Sage.

Boyle, K., \& Reburn J. (2015). Portrait of Serial Killer. Feminist Media Studies, 15(2), 192-207.

Bronfen, E. (1992). Over Her Dead Body: Death, Femininity and Aesthetic. Manchester: Manchester University Press.

Buchwald, E., Fletcher, P., \& Roth, M. (2005). Transforming a Rape Culture. Minneapolis: Milkweed Editions.

Buonanno, M. (2012). La fiction Italiana: Narrazioni televisive e identità nazionale (Italian TV Series: TV Narration and National Identity). Gius: Laterza \& Figli Spa.

Burfoot A., \& Lord S. (2011). Killing Women: The Visual Culture of Gender and Violence. Waterloo, Ont.: Wilfrid Laurier University Press.

Clarke Dillman, J. (2014). Woman and Death in Film, Television and News: Dead but Not Gone. US: Palgrave Macmillan.

Creeber, G. (2015). Killing Us Softly: Investigating the Aesthetics, Philosophy and Influence of Nordic Noir Television. Journal of Popular Television, 3(1), 21-35.

Dyer, R. (1985). Entertaiment and Utopia. In B. Nichols (Ed.), Movies and Methods (Vol. 2, pp. 220-232). Berkeley: University of California Press.

Eures. (2015). Terzo Rapporto su Caratteristiche, dinamiche e profili di rischio del femminicidio in Italia (Third Report on Femicide Features, Dynamics and Risk Profiles in Italy). Roma: Eures.

Gaudio, R., Giomi, E., Massidda, L., \& Menduni, E. (2017). La rappresentazione della figura femminile nella programmazione televisiva della Rai. Anno 2016 (Monitoring the Female Representation in Rai TV Programs, year 2016). Retrieved from http://www.rai.it/dl/docs/1492171115958Monitoraggio_figura_femminile_2016__Ministero_DEF_.pdf

Gili, G. (2006). La violenza televisiva. Logiche, forme, effetti (Violence in Television: Logics, Forms and Effects). Rome, Carocci. 
Giomi, E. (2015a). Quaderno di appunti di gender e media (Notes on Gender and Media). Editore: Pigreco Edizioni.

Giomi, E. (2015b). Tag femminicidio: La violenza letale contro le donne nella stampa italiana (Femicide Tag: Lethal Violence against Women in the Italian Press). Problemi dell'informazione (The Issues with Information), 3, 549-574.

Giomi, E., \& Magaraggia, S. (2017). Relazioni brutali (Brutal relations). Bologna: Il Mulino.

Gius, C., \& Lalli, P. (2014). I loved her so much, but I killed her: Romantic Love as a Representational Frame for Intimate Partner Femicide in three Italian Newspapers. Journal for Communication Studies, 7(2), 53-75.

Grasso, A., \& Penati, C. (2016). La nuova fabbrica dei sogni: Miti e riti delle serie tv americane (The New Dream Factory: Myths and Rituals in American TV Series). Editore: Il Saggiatore.

Innocenti, V., \& Pescatore, G. (2008). Le nuove forme della serialità televisiva. Storia, linguaggio e temi (The New Shapes of TV Seriality: History, Language and Themes). Editore: Archetipo Libri.

Jermyn, D. (2003). Woman with a Mission: Lynda La Plante, DCI Jane Tennison and the Reconfiguration of TV Crime Drama. Retrieved from https://doi.org/10.1177/1367877903006001003

Jermyn, D. (2016). Silk Blouses and Fedoras: The Female Detective, Contemporary TV Crime Drama and the Predicaments of Postfeminism. UK, University of Roehampton: CMC (Crime Media Culture).

Marini, R. (2006). Mass media e discussione pubblica. Le teorie dell'agenda setting (Mass Media and Public Discussion: The Theories of Agenda Setting). Rome: Laterza.

McQuail, D. (2007). Sociologia dei media. Bologna: Il Mulino.

Moorti, S. (2002). The Colour of Rape: Gender and Race in Television's Public Spheres. Albany: State University of New York Press.

Mulvey, L. (1999). Visual Pleasure and Narrative Cinema. In L. Braudy, \& M. Coehn (Eds.), Film Theory and Criticism: Introductory Readings (pp. 833-844). New York: Oxford UP.

Pinedo, I. (1997). Recreational Terror: Woman and Pleasures of Horror Film Viewing. Albany, NY: SUNY Press.

Pravadelli, V. (2006). Feminist film theory e gender studies. In P. Bertetto (Ed.), Metodologie di analisi del film (pp. 59-102). Bari, Roma: Laterza.

Projansky, S. (2001). Watching Rape: Film and Television in Postfeminist Culture. New York: New York University Press.

Sawday, J. (2013). The Body Emblazoned: Dissection and the Human Body in Renaissance Culture. London and New York: Routledge.

Scaglioni, M., \& Barra, L. (2013). Tutta un'altra fiction. La serialità pay in Italia e nel mondo. Il modello Sky (A Whole Other Fiction: Pay-per-view Seriality in Italy and in the World. The Sky Model). Rome: Carocci.

Scheufele, D. A. (1999). Framing as a theory of media effects. Journal of Communication, 49, 103-122.

Shepherd, L. J. (2012). Gender, Violence and Popular Culture: Telling Stories. New York: Routledge.

Sotirovic, M. (2003). How Individuals Explain Social Problems: The Influences of Media Use. Journal of Communication, 53, 122-137.

Tait, S. (2006). Autoptic Vision and the Necrophilic Imaginary in CSI. International Journal of Cultural Studies, 9(1), 45-62.

Tasker, Y. (1993). Spectacular Bodies: Gender, Genre and the Action Cinema. New York: Routledge.

Thornham, S. (1999). Feminist Film Theory: A Reader. New York: New York University Press.

Thornham, S., \& Purvis T (2005). Television Drama: Theories and Identities. Basingstoke: Palgrave Macmillan,

Tota, A. L. (2008). Gender e media: Verso un immaginario sostenibile (Gender and Media: Towards a Sustainable Imaginary). Roma: Meltemi.

Virdi, J. (2006). Reverence, Rape-and then Revenge: Popular Hindi Cinema's Women's Film. In A. Burfoot, \& S. Lord Waterloo (Eds.), Killing Women: The Visual Culture of Gender and Violence (pp. 251-272). Waterloo, Ont.: Wilfrid Laurier University Press. 